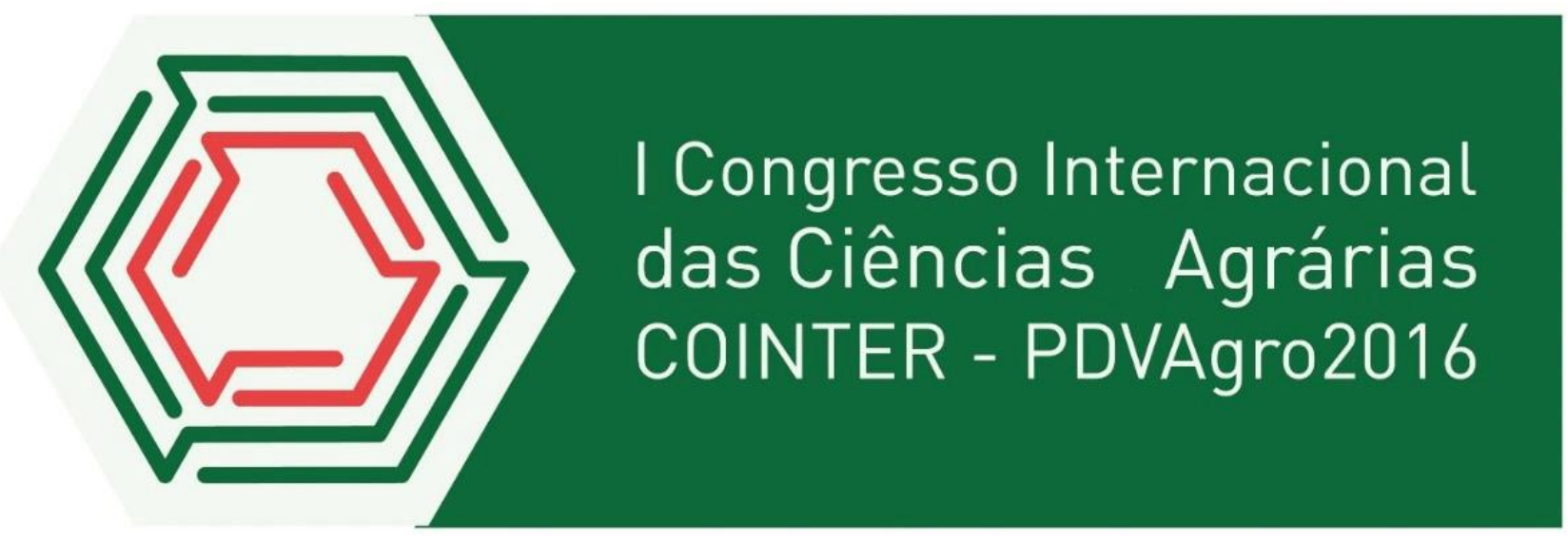

\title{
ELABORAÇÃO E AVALIAÇÃo FÍSICO-QUIMICA DE REQUEIJÃo CREMOSO COM REDUZIDO TEOR DE SÓDIO
}

\author{
Apresentação: Pôster
}

\begin{abstract}
Vanúsia Medeiros Silva ${ }^{1}$; Ana Cláudia Siqueira Silva ${ }^{2}$; Cicero Wanderson G. Farias ${ }^{3}$; Jânio E. de Araújo Alves ${ }^{4}$; Cristiane Ayala de Oliveira ${ }^{5}$
\end{abstract}

\section{Introdução}

A legislação brasileira define requeijão cremoso por ser um queijo cremoso fundido, obtido por fusão de massa de coalhada dessorada e lavada obtida por coagulação enzimática ou ácida do leite, é um produto tipicamente brasileiro, sua origem se deu de fabricações caseiras, como aproveitamento do leite coagulado pela ação dos microrganismos naturais. Este trabalho foi desenvolvido com o intuito de elaborar, caracterizar e avaliar sensorialmente dois tipos de requeijão cremoso produzidos de forma artesanal, sendo uma formulação com reduzido teor de sódio. Foram elaboradas duas formulações $\mathrm{F} 1=100 \% \mathrm{NaCl}$ e $\mathrm{F} 2=50 \%$ de $\mathrm{NaCl}$ e $50 \%$ de $\mathrm{KCl}$. Nos requeijões elaborados, foram realizadas análises físico-químicas de umidade, proteína, cinzas, pH, acidez, teor de cloretos, lactose e gordura. Com os dados coletados, foi realizada análise de variância (ANOVA) e aplicou-se o teste de comparação de médias (Tukey) a 5\% de significância, utilizando o programa o programa estatístico ASSISTAT versão 7.7, 2014. Constatou-se que as amostras diferiram estatisticamente entre si $(\mathrm{p}<0,05)$ apenas para o conteúdo de gordura, cloretos totais, cloretos em $\mathrm{NaCl}$ e pH. Apesar de haver diferença na caracterização físico-química dos produtos quanto ao teor

\footnotetext{
${ }^{1}$ Graduanda do Curso de Tecnologia em Alimentos, IF Sertão- PE - Campus Salgueiro. ${ }^{2}$ Graduanda do Curso de Tecnologia em Alimentos, IF Sertão- PE - Campus Salgueiro. ${ }^{3}$ Graduando do Curso de Tecnologia em Alimentos, IF Sertão- PE - Campus Salgueiro.

${ }^{4}$ Técnico em Agroindústria do Curso de Tecnologia em Alimentos, IF Sertão- PE - Campus Salgueiro.

${ }^{5}$ Profa Doutora, Docente do Curso de Tecnologia em Alimentos, IF Sertão- PE - Campus Salgueiro. E-mail: cristiane.ayala @ifsertao-pe.edu.br
} 
de cloretos, não foi identificada diferença sensorial significativa entre as amostras de requeijão. Podendo ser satisfatoriamente substituído por sua versão com teor de sódio reduzido.

\section{Fundamentação Teórica}

A legislação brasileira define requeijão cremoso por ser um queijo cremoso fundido, obtido por fusão de massa de coalhada dessorada e lavada obtida por coagulação enzimática ou ácida do leite, com adição de creme de leite e/ou gordura anidra de leite e/ou "butteroill" e/ou manteiga (BRASIL, 1997). É um produto tipicamente brasileiro, sua origem se deu de fabricações caseiras, como aproveitamento do leite coagulado pela ação dos microrganismos naturais (PEREIRA, 2013).

Tem ocupando importante lugar no consumo de lácteos, motivo pelo qual tem se tornado um dos focos das pesquisas de desenvolvimento de produtos, pois nos últimos anos a produção nacional de requeijão cremoso aumentou aproximadamente $134,83 \%$, chegando a serem produzidas cerca de 62.700 toneladas de requeijão em 2010 (ABIQ, 2011). A redução de sódio para o requeijão pode ser obtida pela combinação de $\mathrm{NaCl}$ e $\mathrm{KCl}$ e a substituição de parte do sal fundente tradicionalmente utilizado (à base de fosfatos de sódio) por outros à base de fosfatos de potássio e/ou cálcio e/ou sódio. (VAN DENDER et al., 2012).

Atualmente o consumidor, vem se posicionando positivamente diante do apelo das organizações mundiais de saúde para a ingestão de alimentos mais saudáveis e com teores de sal limitados. De acordo com a Política Nacional de Alimentação e Nutrição o consumo diário de sal não deve ultrapassar a ingesta de $5 \mathrm{~g} /$ dia. Desta forma, o desenvolvimento de produtos que atendam às necessidades da saúde do consumidor tem sido de grande importância no mercado de alimentos. Para isso pesquisas vêm sendo realizadas em relação à redução ou adição de algum ingrediente para melhorar sua qualidade nutricional.

A substituição de ingredientes pode trazer outros benefícios, além da redução do custo, como proporcionar características funcionais ao produto (VAN DENDER, 2006). A geração de novos produtos permitiu o acesso do consumidor de baixa renda ao sabor semelhante ao requeijão, estimulando a competitividade entre as empresas e o atendimento de públicos diversos.

\section{Metodologia}




\section{Elaboração do Requeijão Cremoso}

O leite utilizado para fabricação da massa foi adquirido no comercio local, sendo armazenado sob temperatura de $4^{\circ} \mathrm{C}$ no laboratório de produtos de origem animal do Instituto Federal de Educação, Ciência e Tecnologia do Sertão Pernambucano - Campus Salgueiro. O leite foi submetido à coagulação enzimática com quimisona, a massa foi obtida após 1 hora, dessorada e prensada, para posteriormente ser fundida com os demais ingredientes da formulação de requeijão cremoso. A gordura utilizada na fabricação de requeijão foi creme com teor de gordura padronizado em $55 \%$, já sendo adquirida pasteurizada. Foram elaboradas duas formulações $\mathrm{F} 1=100 \% \mathrm{NaCl}$ e $\mathrm{F} 2=50 \%$ de $\mathrm{NaCl}$ e $50 \%$ de $\mathrm{KCl}$.

\section{Elaboração do Requeijão Cremoso}

As amostras foram submetidas à ensaios físico-químicos, os quais foram executados em delineamento experimental, com três repetições para cada marca, afim de se determinar o teor de sólidos solúveis, gordura, densidade, ponto de congelamento, proteína, lactose, acidez e $\mathrm{pH}$. O teor de acidez foi expresso em porcentagem (\%) de ácido láctico e o teste realizou-se por titulação, com a utilização de hidróxido de sódio e fenolftaleína. $\mathrm{O}$ pH foram realizadas em triplicata, por leitura direta através do aparelho pHmetro e a determinação do teor de SST (sólidos solúveis totais) realizou-se através de leitura direta em refratômetro de portátil. Para a determinação dos parâmetros de gordura, densidade, proteína e sólidos solúveis foi utilizado o analisador de leite, com três repetições previamente calibrado (Lactoscan, MMC Multi Master Colect, Entelbra Ltd.®). Os dados obtidos foram submetidos à análise de variância pelo teste $\mathrm{F}$ e, quando significativos, submetidos à comparação entre as médias pelo teste de Tukey a 5\% probabilidade. Sendo analisados por meio do programa estatístico ASSISTAT versão 7.7, 2014 (SILVA, 2014).

\section{Resultados e Discussões}

Foram constatadas diferenças estatísticas significativas $(\mathrm{p}<0,05)$ entre as duas formulações de requeijão elaboradas para as variáveis: gordura, cloretos, cloretos em $\mathrm{NaCl}$ e $\mathrm{pH}$ como pode-se observar na Tabela 1. Os teores de gordura do requeijão cremoso F1 e F2 variaram de 5,15\% a 5,78\%. Comparado aos valores da literatura de Van Dender et. al (2006) Os teores de gordura variaram de $0,81 \%$ a 1,03\%. Apesar de não ter havido adição de gordura na massa básica, a mesma apresentou teor de gordura de $0,989 \%$. O conteúdo de gordura influencia o sabor, a textura, a 
cremosidade, a aparência e a palatabilidade, pois o requeijão constitui sistema complexo composto de proteínas, gordura, água, sais minerais e outros ingredientes (PRENTICE, 1992).

Tabela 1: resultados das análises físico-químicas das diferentes marcas de requeijão cremoso. Fonte: Própria

\begin{tabular}{ccc}
\hline & Sal Normal & $50 \%$ de cloreto de sódio \\
\hline Umidade \% & $68,42 \pm 0,25^{\mathrm{a}}$ & $68,10 \pm 0,34^{\mathrm{a}}$ \\
Cinzas \% & $2,48 \pm 1,00^{\mathrm{a}}$ & $0,82 \pm 0,31^{\mathrm{a}}$ \\
Proteína \% & $13,08 \pm 0,03^{\mathrm{a}}$ & $13,04 \pm 0,10^{\mathrm{a}}$ \\
Gordura \% & $5,15 \pm 0,24^{\mathrm{b}}$ & $5,78 \pm 0,23^{\mathrm{a}}$ \\
Carboidratos\% & $10,87 \pm 0,12^{\mathrm{b}}$ & $11,26 \pm 0,21^{\mathrm{a}}$ \\
Cloretos \% & $0,40 \pm 0,16^{\mathrm{a}}$ & $0,24 \pm 0,13^{\mathrm{b}}$ \\
Cloretos em NaCl \% & $0,65 \pm 0,05^{\mathrm{a}}$ & $0,39 \pm 0,02^{\mathrm{b}}$ \\
pH & $6,38 \pm 0,29^{\mathrm{b}}$ & $6,55 \pm 0,21^{\mathrm{a}}$ \\
Acidez & $4,66 \pm 0,57^{\mathrm{a}}$ & $4,66 \pm 0,57^{\mathrm{a}}$ \\
Lactose \% & $4,63 \pm 0,04^{\mathrm{a}}$ & $4,57 \pm 0,16^{\mathrm{a}}$ \\
\hline a-b: letras diferentes na mesma linha, as médias foram significativas pelo teste de Tukey (p<0,05)
\end{tabular}

Os valores de pH apresentaram-se altos entre 6,38 e 6,55, não estando dentro dos limites indicados. Rapacci (1997) determinou o $\mathrm{pH}$ de oito marcas comerciais de requeijão mais consumidas e encontrou grandes variações de resultados, sendo o valor médio de pH acima de 6,0. $\mathrm{O}$ pH dos requeijões processados com massa obtida por acidificação direta e adicionados de sal emulsificante, pode se apresentar muito elevado (faixa de 6,0 a 6,35), o que pode comprometer a vida útil do produto final (RAPACCI, 1997). Os valores dos cloretos em $\mathrm{NaCl}$ diferiram um do outro estando entre $0,64 \%$ e $0,39 \%$. Sendo que o requeijão que foi adicionado o sal normal obteve valores maiores de $\mathrm{NaCl}$ e que o outro com a concentração reduzida. A Portaria 359/1997/MA estabelece que o requeijão cremoso deverá conter no máximo $65 \mathrm{~g} / 100 \mathrm{~g}$ de umidade (BRASIL, 1997). Os valores de umidade estão entre $(68,42$ e 68,10) do requeijão cremoso F1 e F2 está acima do valor permitido pela legislação. Comparando o requeijão com sal normal a formulação com $50 \%$ de cloreto de sódio, foram constatadas diferenças estatisticas ( $>>0,05)$. De acordo com Oliveira (1990) um requeijão cremoso típico apresenta cerca de $45 \%$ de umidade. Com relação ao conteúdo mineral não houve diferença $(\mathrm{P}>0,05)$ entre as duas formulações. Os valores expressos, na Tabela 1, foram inferiores aos relatados por Queiroz (2001) que encontrou 
2,03\% no requeijão tradicional e 2,49 e 2,29\% nos requeijões light. De acordo com Garcia (2005) os valores foram superiores sendo esses 2,31; 2,27; 2,17 e 2,12\%. Em alguns casos a diferença entre os teores de cinzas está relacionada à variação das formulações dos requeijões cremosos. O teor de minerais influencia o grau de fusão e derretimento do requeijão: quanto maior o teor de minerais menor será sua capacidade de derretimento (SILVA, VAN DENDER e MELLO, 2005). Os resultados dos valores das proteínas não diferiram entre si tendo assim valores 13,08 e 13,04. Em outros tabalhos os valores divergiram na pesquisa de SILVA et al. (2012), com requeijão cremoso light ocorreu aumento no teor de proteína entre 10,0 e 19,4\%, explicado pela redução de gordura e umidade que acarretou esse aumento.

\section{Conclusões}

Com os resultados obtidos, pode-se constatar que é possível a elaboração de um requeijão com reduzido teor de sódio, contudo, maiores estudos devem ser realizados a fim de padronizar a formulação e enquadrá-la nos requisitos estabelecidos pela legislação, além da verificação da viabilidade da utilização de outros produtos alternativos.

\section{Referências}

BRASIL. Ministério da Agricultura, Pecuária e Abastecimento. Decreto no 2.244 de 04/06/1997. Altera dispositivos do Decreto $n^{\circ} 30.691$, de 29/03/1952, que aprovou o Regulamento da Inspeção Industrial e Sanitária de Produtos de Origem Animal Brasília, DF, 1997.

GOMES, R. G.; PENNA, A. L. B.; Caracterização de requeijão cremoso potencialmente probiótico pela adição de inulina e proteína de soja. B.CEPPA, Curitiba, v. 28, n. 2, p. 289-302, jul./dez. 2010.

LINS, L. G.; VAN DENDER, A. G. F. ; SPADOTI, L. M., SÁ,P. B. C. R.; ORMENESE, R. C. S. C. ; TRENTO, F. K. H. S.; YOTSUYANAGI, K.; MORGANO, M.; Fabricação de requeijão cremoso sem adição de gordura e com teor reduzido de sódio.

LOPES, C. O.; Uso de especiarias viabiliza a redução do teor de sódio em maionese e requeijão UFLA, 2014.

PEREIRA, F. C.,Estudo tecnológico de requeijão cremoso light com teor de sódio reduzido e adição de fibra alimentar.Uberaba, 2013. Dissertação (Mestrado) - Instituto Federal do Triângulo Mineiro-campus Uberaba, 2013. Disponível em: <http://www.iftm.edu.br/uberaba/cursos/posgraduacao-strictopresencial/alimentos/dissertacoes/arquivos/2013/flavia_correia_pereira.pdf> Acesso em: 10/09/2016.

PRENTICE, J. H. Dairy rheology: a concise guide. Cambridge: VCH, 1992. 165 p. 
RAPACCI, M. Estudo comparativo das características físicas e químicas, reológicas e sensoriais do requeijão cremoso obtido por fermentação láctica e acidificação direta. 1997. 142 p. Tese (Doutorado em Tecnologia de Alimentos) - Faculdade de Engenharia de Alimentos, Universidade Estadual de Campinas, Campinas, 1997.

SILVA, F.A.S. ASSISTAT: Versão 7.7 beta. DEAG-CTRN-UFCG - Atualizado em 01 de abril de 2014. Disponível em . Acessado em: 20 de maio de 2014.

SILVA. A. T.; VAN DENDER, A. G. F.; MELLO, F. M. Capacidade de derretimento de requeijão cremoso obtido por diferentes processos. Revista do Instituto de Laticínios Cândido Tostes, Juiz de Fora, v. 60, n. 345, p. 414-417, 2005.

VAN DENDER, F. G. A. Requeijão cremoso e outros queijos fundidos: tecnología de fabricação, 